\title{
Mature Minors Should Have the Right to Refuse Life-Sustaining Medical Treatment
}

\author{
Melinda T. Derish and Kathleen Vanden Heuvel
}

$\mathrm{I}$ magine that you are a teenager and have cancer. You undergo a year of chemotherapy and after a brief return to normal life, you have a relapse. Your physician says that chemotherapy and radiation therapy could be tried, but a bone marrow transplant (BMT) is your only chance of a real cure. He tells you and your parents that you could die as a result of complications from the transplant, but without it you would only be expected to live one year. You and your family discuss the alternatives and decide to have the transplant. You ask what will happen if the BMT fails, but both your physician and your family tell you that right now you must fight to get better and not think negative thoughts. You do not ask any more questions. The doctor gives your parents the consent form to read over. You look at it as well, but only your parents may sign it.

The preparation necessary before the transplant is worse than you had imagined it would be and you experience painful side effects. You also become fearful because some BMT patients, whom you've heard about through the hospital's patient/family grapevine, went to the pediatric intensive care unit (PICU) this month and never came back. Still, you do not ask your family if these patients died and neither your family nor your doctor ever asks you if you have thought about what you would want done if you were sick enough to need intensive care.

One week after the BMT, before the new marrow has even taken hold in your body, you start to have trouble breathing. Over the next day it gets harder to breathe and becomes difficult to speak more than two words at a time. You are frightened because you feel so hungry for air. As your family watches you struggle to breathe, they become frightened as well. A doctor tells you that you will need help from a ventilator soon and for this they must transfer Journal of Law, Medicine \& Ethics, 28 (2000): 109-124. (C) 2000 by the American Society of Law, Medicine \& Ethics. you to the PICU. You ask them please, do not send you to the PICU, because you do not want to die there. You and your parents look to your doctor, who is obviously worried. Your parents ask the doctor to save you; he says that the ventilator is your only chance.

You are transferred to the PICU and are put into a deep sleep, as the doctor promised, but eventually you wake up enough to realize that your fingers cannot move and your eyelids will not open. You cannot speak, and even a grimace is impossible. You are groggy most of the time. The voices of family members, of certain nurses that you come to recognize, occasional music, a light stroking on your arm-these become the highlights of your existence. Time passes slowly and you lose track of the days. After some weeks you notice that you are more awake than before, yet you still cannot move. Nobody told you that you might be awake but unable to move a muscle. They had promised that you would be asleep. The air goes into your lungs with so much force that you feel like your lungs are going to burst, and you are choking on the tube in your windpipe. The ulcerations in your mouth and throat hurt continuously. Even worse than the pain is the dawning realization that you are dying. You want to ask for more medicine to keep your pain and fear under better control. You want to say goodbye to your family and go home to die, but you cannot move or speak at all. You hear the members of your family whisper to each other and they tell you how much they love you, but you cannot respond to them. You die in the PICU.

\section{Introduction}

The natural reaction to our prologue may be denial, or suspicion that we have presented a melodramatic description of a rare occurrence. In fact, the scenario we have described 
is an all too common reality in the United States. ${ }^{1}$ Widespread denial of this reality is one reason that children remain particularly vulnerable to receiving end-of-life medical care that has never been fully explained to them, and why they receive treatment that they have never made a decision to accept. Another reason is the long-standing assumption made by society and the medical and legal professions that parents are natural and obvious surrogate medical decision-makers for all medical treatment of their children and will always act in their child's best interest. This assumption does not require that there be any examination or assessment of the child's level of maturity, nor does it allow for any degree of autonomy for the mature child. Rather, it allows physicians and the legal profession simply to fall back on the traditional, common law rule that only parents can give permission for medical treatment. As a result all children, regardless of their capacity to understand and make decisions about their medical treatment, are categorically excluded from the legal rights that have developed over the past fifteen years to protect adults from unwanted medical treatment. While the adult's right to refuse medical treatment is "gradually becoming absolute,"2 minors ${ }^{3}$ continue to be denied medical autonomy. This categorical exclusion increases the risk that children will receive unwanted life sustaining medical treatment (LSMT) at the end of their lives.

In order to understand precisely which rights mature minors have been denied it is crucial to define LSMT. LSMT usually refers to sophisticated medical technology, such as mechanical ventilators, intravenous medicines that force the heart to beat, dialysis, etc. It can also mean less dramatic medical intervention, such as artificial feeding. Although LSMT forestalls the moment of death, by definition LSMT can only sustain life. It cannot save life or cure a patient's disease. ${ }^{4}$ This is a crucial distinction, because medical treatment at the end of life often carries high physical and psychological burdens. Its potential benefit can only be measured in relation to the patient's personal values. ${ }^{5}$ The decision to accept or refuse LSMT may determine not only the time of one's death; but also the manner in which that death occurs. Thus, a denial of the mature minor's autonomy to refuse LSMT amounts to denying her the right to decide whether the medical prolongation of life, as it transforms into a prolongation of death, is worth the physical and psychological burdens. ${ }^{6}$

Certainly parents, physicians and lawyers are not conspiring to inflict unwanted LSMT upon children. Rather, it is the cumulative result of a lack of communication between the legal and medical professions, as well as between individual parents, children and physicians. We focus our discussion on chronically ill children who are potentially mature minors (minors with decision making capacity), because this subgroup of pediatric patients has the best opportunity and reason to make their own decisions about
LSMT. We begin with a demonstration of how LSMT can be inflicted upon a mature minor, despite the best intentions of her parents and physician.

\section{A chronically ill child's end-of-life medical care}

\section{Consent to a potentially fatal treatment}

Despite the centrality of informed and voluntary consent to the ethical medical treatment of a patient, there are several obstacles to its application in the context of the mature minor struggling with a potentially fatal disease. Recall that the physician in our Prologue did not suggest that the patient should give her own informed consent to the BMT, or to her transfer to the PICU. Even though the patient was an adolescent who had lived with her cancer and its treatments for a year and she was involved in the ongoing discussions about her disease, relapse, and the BMT, the physician sought and received the consent of the parents and not of his patient. At common law minors do not have the legal capacity to consent to medical treatment. ${ }^{7}$ Instead, the law generally presumes that only parents have the authority to make medical decisions for their minor children and that in doing so they will act in their child's best interest. In addition to the absence of her legal right to give informed consent (or its counterpart, informed refusal), neither our hypothetical patient nor her parents were given the opportunity to fully comprehend and weigh the treatment options related to the possibility of dying. Patients with life-threatening diseases often do not have frank discussions with their physician about what will happen if the treatment options fail and death is likely. ${ }^{8}$

Although BMT has a substantial risk of respiratory failure $^{9}$ and although respiratory failure after BMT has a huge mortality rate, ${ }^{10}$ neither the patient's physician nor her parents were willing to discuss death. Physicians and parents rarely do discuss death with chronically ill children. ${ }^{11}$ Thus, the patient described in our scenario had no way to anticipate what would happen to her or to discuss her own desires for end-of-life care. ${ }^{12}$ Failure to discuss the possibility of the patient's death before respiratory distress and the ensuing panicky scenario of emergency transfer to the PICU effectively precluded the patient and her family from considering possible alternative therapeutic options, such as palliative care or hospice.

It is difficult for any patient-child or adult-to make well-informed, rational choices about treatment options during severe respiratory distress. By the time this patient's pneumonia had worsened to the stage where she needed a ventilator, the opportunity to provide the information necessary for her to give her own informed consent to LSMT was long past. When the patient suddenly spoke her wishes for the first time, saying she did not want to go to the PICU or to die there, it was too late in the course of events to plan 
for hospice. During a time of severe and rapid deterioration in respiratory status there would be only two treatment options: either the patient could be supported with mechanical ventilation, or she could be treated with the tranquilizers and narcotics needed to alleviate severe air hunger and allowed to die. In reality, the latter treatment was already precluded for this child because parents rarely are able to make an emergency decision to let their child die.

\section{The realities of death in the ICU}

The patient we described was frightened and in pain, yet unable to request any relief because she was therapeutically paralyzed. While experts know that "the terror of awake paralysis is unthinkable," even trained observers may have difficulty recognizing inadequate sedation when a patient is pharmacologically paralyzed. ${ }^{13}$ Although not all patients in the ICU receive therapeutic paralysis, feeling what one author aptly termed "paralyzed with pain" 14 has a higher likelihood of happening to those patients who are the sickest, i.e., the most likely to die.

Patients who will ultimately die while receiving ventilator support commonly develop deteriorating lung function during their ICU course, necessitating increased ventilator pressures in order to deliver sufficient mechanical assistance to the lungs' life-sustaining exchange of oxygen and carbon dioxide. The higher ventilator pressures run the risk of pushing the oxygen mixture into the air sacs of the lungs, the alveoli, under such force that they may rupture, causing air leakage outside the lung. This air is then trapped between the lung and the rib cage, a painful and sometimes fatal condition called a pneumothorax. In the setting of high ventilator pressures, optimal sedation of the patient is essential to achieve good synchronization between the ventilator and patient because, if the patient's own efforts to breathe conflict with the ventilator breaths, this further raises pressure within the alveoli. However, if this approach does not keep ventilator pressures below a dangerous threshold, therapeutic paralysis is used. Patients are given drugs known as neuromuscular blocking agents that cause complete skeletal muscle flaccidity but have absolutely no effect upon the brain.

Given paralytic drugs alone, a patient would be fully conscious but completely paralyzed. There have been many case reports of patients who underwent surgery and awoke while they were still paralyzed, a situation called intraoperative awareness. To detect when the patient is awake while paralyzed, doctors must rely upon the physiologic signs of the patient's pain or anxiety-elevations of heart rate and blood pressure. However, even experienced anesthesiologists cannot always detect periods of intraoperative awareness ${ }^{15}$ and experts believe it is an underreported phenomenon. ${ }^{16}$ The challenge of preventing awake paralysis is even greater in the ICU environment. ${ }^{17}$ One sur- vey from an adult ICU reported that $36 \%$ of patients surveyed recalled experiencing pain, fear, or both while under therapeutic paralysis. ${ }^{18}$ Only one pediatric study has attempted to identify pediatric patients' experience of therapeutic paralysis, ${ }^{19}$ but we know that paralytic drugs are often used in PICUs. ${ }^{20}$

Since all surveys must necessarily be of patients who survived to describe their experience, we cannot know the incidence of inadequate sedation and pain control among patients who ultimately died in the $\mathrm{ICU}$, but it is likely to be even higher than the incidence reported in surveys. Nonsurvivors of the ICU often have longer ICU stays. ${ }^{21}$ During longer hospital stays, patients develop drug tolerance-a need for increasing doses of tranquilizers and narcotics to achieve the same level of sedation and pain control. The ICU team still has only the same signs to follow that the anesthesiologist had in the operating room, but during an ICU course many patients, even if they are terrified or in severe pain, may not be physiologically capable of developing the high blood pressure which could communicate their plight to their health care providers. ${ }^{22}$ Since drug requirements for control of the same type of pain can vary widely from patient to patient, it is a matter of guesswork to determine the optimal drug dosage for a patient who is paralyzed for days or weeks. It may be impossible to judge the paralyzed patient's level of comfort and experts have recently argued that therapeutic paralysis should be stopped in almost all dying patients. ${ }^{23}$

Medical paralysis is frequently employed in the ICU, ${ }^{24}$ but it is a subject that is not often discussed between doctors and patients and it is not a standard topic on advance directive forms. Physicians are not likely to discuss with parents the possibility that their serene appearing child may be in undetected pain or terror, that unless their child is not paralyzed the physician and parents cannot know whether the dying child is suffering. Without paralysis, however, the ventilator could cause a pneumothorax, which would be either fatal or, if treated with chest tubes, could leave the patient in more pain than before. Thus, stopping paralysis in the setting of dangerously high ventilator pressures cannot be standard medical treatment so long as the family's priority is to prolong the child's life.

If the family agrees that comfort is a higher priority than the attempt to prolong life, then paralysis can be stopped. At this juncture, physicians must help the family accept their child's impending death and readjust the goals of treatment. ${ }^{25}$ Now reconsider the patient we described in the prologue. If her physician had initiated early and repeated discussions before the pneumonia began he would have been able to give the patient and her family sufficient time and information to give a truly informed consent. The child and her family could have worked out how she wanted to balance the sometimes mutually exclusive goals of sustaining life and avoiding suffering. 


\section{Advance directives}

Advance directives allow adults to continue to exercise their right to secure or avoid medical technology if they become unconscious or otherwise incapable of making health care decisions. The role of an advance directive is to provide guidance to a patient's surrogates and health-care providers with regard to the personal decisions that the patient would have made about their own end-of-life care. Advance directives may be formatted as a "living will," as the designation of a proxy agent responsible for making medical decisions if the declarant becomes unable to make her own decisions (patient surrogate or attorney-in-fact), or as both. A living will type document provides specific instructions about the individual's medical treatment decisions regarding end-of-life care. ${ }^{26}$ Designating a health care agent, via the durable power of attorney for health care or health care proxy, authorizes that specific person to act as the patient's surrogate medical decision-maker in the event of future incapacity. This helps avoid the confusion and conflict that may arise if multiple family members are involved in an incompetent patient's end-of-life care. However, even severely ill patients are not likely to have executed advance directives. ${ }^{27}$ Thus for most patients, unless they have designated otherwise by a durable power of attorney, once they become incapacitated it is usually the nearest family member who will become the surrogate medical decision-maker. There are two standards by which surrogates make medical treatment decisions for their incompetent family members: the substituted judgment standard and the best interests standard. ${ }^{28}$ The substituted judgment standard requires that the "surrogate attempt to reach the decision that the incapacitated person would make if he or she were able to choose"29 while the best interests standard "does not rest on the value of self-determination but solely on protection of patients' welfare." 30 The standard of substituted judgment is generally considered preferable to the best interests standard and should be used by surrogates whenever possible. ${ }^{31}$

Although an incapacitated patient's prior discussions and lifestyle could possibly be used as evidence of her own values, when surrogates must make medical treatment decisions it is the living will portion of the advance directive that can most incontrovertibly inform the substituted judgment and provide the clear and convincing evidence that may be necessary to legally safeguard the patient's wishes. The advance directive also may provide some reassurance to a patient's surrogates and physicians. Honoring a patient's advance directive, even if it results in hastening the patient's death, will not result in legal reprisals for the patient's family or physician. ${ }^{32}$

Partially in response to the U.S. Supreme Court's decision in Cruzan, which held that states can require clear and convincing evidence ${ }^{33}$ of a patient's wishes before allowing surrogates to refuse or discontinue medical treatment on an incompetent patient's behalf, Congress passed the Patient Self Determination Act (PSDA). ${ }^{34}$ The PSDA requires each state to develop a written description of that state's statutory and common law concerning a person's rights to make health care decisions and complete advance directives, ${ }^{3 s}$ and further requires Medicare and Medicaid participating organizations to provide written information to patients concerning these rights, including the right to consent to or refuse medical treatment and to formulate advance directives under state law. ${ }^{36}$ Every state now has some form of advance directive statute. ${ }^{37}$ The PSDA, however, currently applies only to adult patients and state advance directive statutes do not apply to minors.

\section{Minors are presumed incompetent}

The adult's right to execute an advance directive is derived from the legal presumption that adults are competent to make their own decisions about activities that affect themselves ${ }^{38}$ including decisions to consent to or refuse LSMT. ${ }^{39}$ Those who would force an adult patient to receive unwanted medical treatment have the burden of proving that a patient is incompetent rather than the patient having to prove that he is competent. ${ }^{40}$ Minors, however, are in precisely the opposite position. At common law they are presumed legally incompetent to give their own consent to medical treatment. ${ }^{41}$ Although the common law presumes that minors have the same right to bodily integrity as adults, only their parents are allowed to exercise this right. Parental authority to make medical decisions for their children is also based upon a general, legal presumption that parents will act in the best interests of their children and upon the Constitutional right of privacy in family matters. ${ }^{42}$ The result of this strong protection of parental authority is that although minors are protected from invasion of their bodily integrity by the same doctrine of informed consent as adults, they have no legal way to exercise this protection independently. Even if a minor were to be fully informed of her condition and were to understand the consequences and give her refusal of, or consent to medical treatment such as LSMT, that refusal or consent would not be valid as a matter of law. ${ }^{43}$

Although parental autonomy to make medical decisions for their children is not unlimited, neither of the two most commonly invoked exceptions to the presumption of a minor's legal incompetence and to the requirement of parental consent involve an examination of a minor's own capacity to make medical decisions. In an emergency, a physician may proceed with treatment without the parents' consent, ${ }^{44}$ because their consent is implied. ${ }^{45}$ In the "medical neglect" exception, the State intervenes under its power as parens patriae and its strong interest in preserving life when a minor's parents refuse life saving medical treatment 
for their child. ${ }^{46}$ This State interference with parental autonomy is justified by the presumption that refusal of life saving treatment is clear evidence that parents are not acting in the child's best interest. In both the emergency and medical neglect exceptions to the parental consent requirement the minor's own thoughts, preferences, and decision making capacity are legally irrelevant.

The presumptions that only parents can legally consent to or refuse medical treatment for their children and that a minor's own decision making capacity is legally irrelevant are so strong that physicians often see little point in discussing LSMT with their pediatric patients. In fact, the current system actually creates a disincentive for physicians even to discuss end-of-life care with minors. If a physician were to examine a patient and to conclude that she had full capacity to understand her medical condition and to make her own choices about end-of-life care, the physician would have no way legally to effectuate his patient's choices if her parents disagreed. This potential for conflict places the physician in an extremely difficult position, because once a physician discusses end-of-life care with his patient and she articulates her choices, a physician has an ethical obligation to give serious weight to these choices. ${ }^{47}$ If the physician were to honor the minor patient's choices over the parents' objection he could face severe legal reprisals. ${ }^{48}$ If, on the other hand, the physician carried out the parents' wishes he would have to ignore his ethical obligation to his patient. It is, therefore, safer for physicians to avoid discussing LSMT with their minor patients, rather than to risk potentially irreconcilable ethical and legal consequences. To avoid confronting this dilemma, the medical and legal systems have tended to act on the presumption that physicians have no legal obligation to talk to their pediatric patients about medical treatment. As one Texas court put it, “...a physician cannot be required to make full disclosure to a minor, when a minor cannot give legally effective consent. "The law does not require a vain or useless act."'49

In the last twenty years, however, studies have indicated that "adolescents, with some exceptions, are capable of making major health decisions and giving informed consent." ${ }^{\circ 0}$ In light of this knowledge, it has become increasingly difficult for physicians, lawyers and judges to sustain the position that a minor's actual decision making capacity is legally irrelevant, simply because her consent is not legally effective. As a result, both the medical and legal professions have begun to confront the dilemma created by the current system.

\section{Medical view of minor's capacity}

In 1989 the Journal of Pediatrics published two influential companion pieces on this subject. The first, "Children as Decision Makers: Guidelines for Pediatricians," ${ }^{51}$ argued that when children are faced with a very high stakes choice "the child's concerns are central and the child's decisional role should be enhanced and ultimately dispositive." 52 The second, "A Proposal Concerning Decisions to Forgo LifeSustaining Treatment for Young People," ${ }^{53}$ concluded that "the physician is obligated to determine the maturity level in the seriously ill juvenile and to facilitate the patient's self determination." 54 The author's proposal, a logical outgrowth of his years of clinical experience caring for chronically ill children, was that "if a minor has experienced an illness for some time, understands it and the benefits and burdens of its treatment, has the ability to reason about it, has previously been involved in decision making about it, and has a comprehension of death that recognizes its personal significance and finality, then that person, irrespective of age, is competent to consent to forgoing life-sustaining treatment." 55

Other pediatric care groups have confronted the question of the autonomy of minor patients with decision making capacity as well. The American Academy of Pediatrics (AAP) Committee on Bioethics published three position statements that recognized that chronically ill children have the capacity to make decisions about their end-of-life medical treatment and included guidelines for physicians with minor patients who wished to forgo LSMT. ${ }^{56}$ In a statement entitled "Caring for Gravely Ill Children," a group of representatives from medical and nursing schools concluded that an older child could have "the capacity to understand the consequences of a choice and the ability to assess his or her best interests." 57 Additionally, the Midwest Bioethics Center (MBC) Task Force on Health Care Rights for Minors proposed that all persons with decisional capacity should have the right to make health care decisions. The MBC created a model that addressed the spectrum of children's developing capacity by dividing children into three categories: minors without capacity to participate in any meaningful way (e.g. infants through pre-school years), minors with a developing capacity to participate in decision making, and minors who have the capacity to make most health care decisions. ${ }^{58}$

\section{Why a physician's determination that a minor has decision making capacity is not enough to insure that the minor can legally make autonomous LSMT decisions}

The terms capacity and competence are often used interchangeably, but are not synonymous. While physicians regularly make determinations of their patients' decision making capacity, only a judge can declare a patient legally competent. Court cases questioning an adult's decision making capacity usually arise only when there is disagreement between the patient and the physician about the course of treatment (e.g. adult wishes to forgo LSMT, physician thinks patient should have it). Otherwise, a physician's good faith 
determination of decision making capacity is presumed to be correct. Since minors are presumed incompetent, however, the legal status of a physician's determination of a minor's decision making capacity is highly uncertain.

Although the AAP's guidelines propose that minors with decision-making capacity should be informed of their medical conditions and treatment options and allowed to make high stakes medical decisions such as refusing LSMT, the AAP and the other medical commentators who have addressed this issue stop short of explaining how physicians are to implement these guidelines. The guidelines clearly and straightforwardly define decision making capacity as "(1) the ability to understand and communicate information relevant to a decision; (2) the ability to reason and deliberate concerning the decision; and (3) the ability to apply a set of values to a decision that may involve conflicting elements." ${ }^{59}$ The implication is that physicians will use this definition of capacity and, with possible consultation from specialists in developmental psychology or psychiatry, they will assess and document the capacity of their minor patients to make their own decisions about LSMT. ${ }^{60}$ Nowhere, however, does the AAP discuss who would make the final determination of whether a minor can consent to or refuse LSMT of her own accord. Rather, the AAP states the general principle that "emancipated minors" and "those who have been judged mature for purposes of medical decisions" may refuse unwanted treatment, including LSMT. ${ }^{61}$ In fact, however, these two categories of minors are quite different.

Emancipation is a formal legal status granted to minors who live separate from their parents or who meet a variety of other criteria. In many states an emancipated minor would have the legal status of an adult and would therefore be released from the parental consent requirements. ${ }^{62}$ There would be no need for an assessment of capacity. On the other hand, an unemancipated minor whose physician has determined that she has decision making capacity still has no legal status to make her own medical decisions in most states. ${ }^{63}$ While the AAP refers to the minor who is "judged," "assessed," or "recognized" 64 mature, they do not say whether this judgment of the minor's maturity is the same as the attending physician's determination of her capacity. Does the AAP expect that the physician will make an initial assessment of the minor's actual capacity, which must then be followed by a judicial determination of legal competence? And if so, how does the $\mathrm{AAP}$ propose a physician or a pediatric patient obtain this judicial determination? The AAP statements did not address these difficult questions.

\section{The legal community's response to the dilemma posed by AAP Guidelines}

As early as 1973, Walter Wadlington ${ }^{65}$ assumed that it would be up to the physicians to determine whether the minors they were treating were capable of giving their own consent. While he expressed some concern that this trend required physicians to conduct subjective evaluation of the minors in order to decide whether they were able to give informed consent to these various treatments, he stated that the "principal emphasis [was] on enabling minors to get to physicians who [would] be able to treat them without fear of civil liability except in instances of negligence." ${ }^{66} \mathrm{Al}-$ though Wadlington's prediction has not been fully realized there is considerable evidence that the legal system is aware of the dilemma posed by the fact that adolescents are considered legally incompetent to make medical treatment decisions. For instance, since the 1960 s states have continued to pass laws that allow minors to consent to a variety of medical treatments, including mental health care for drug and alcohol dependency and treatment of sexually transmitted diseases. ${ }^{67}$ These statutes are often viewed as legislative recognition of a more enlightened view of minors, in which they are seen as mature enough to give their own consent to medical treatment. ${ }^{68}$ Others have chosen to view these statutes as isolated exceptions to the parental consent rule, ${ }^{69}$ or as "largely rooted in expediency,"70 rather than recognition of minors' potential for decision making capacity. Either way, however, state legislatures have shown willingness to abrogate the parental consent requirement when there is a perceived need for minors to be able to consent to medical treatment.

While the United States Supreme Court has never specifically addressed the question of whether minors have a Constitutional right independently to consent to or refuse medical treatment, the Court's abortion consent cases suggest that a minor's decision making capacity is, in fact, legally relevant to the question of whether she has a right to make autonomous decisions about her medical treatment. The Court declared two different states' parental consentto-abortion statutes unconstitutional, in part because they did not provide a pregnant minor with a judicial proceeding that allowed her to demonstrate her maturity to make the abortion decision. ${ }^{71}$ The Court created a constitutional context for the idea that a minor's autonomy for medical decision making should be tied to her capacity. As the Court said in Bellotti v. Baird "[s]tates cannot require parental consent for abortion unless they also provide a judicial bypass procedure that entitles pregnant girls to demonstrate their maturity and make their own decisions." 72 The volatile abortion arena has always been a difficult area from which to draw broad conclusions about the medical autonomy of minors, ${ }^{73}$ but these decisions call into question the bright line rule of legal capacity and indicate that "[c]onstitutional rights do not mature and come into being magically only when one attains the state-defined age of majority. Minors, as well as adults, are protected by the Constitution and possess constitutional rights." 74

Although the legal issues of when and under what cir- 
cumstances minors can refuse and consent to medical treatment remain unresolved, it is also significant that lawyers and judges increasingly assume that the mature minor must be treated differently by physicians and the courts. For instance, by the mid 1980s a major legal text for them advised physicians to consider whether their patient's age, cognitive maturity and ability to understand "the items of information required by the doctrine of informed consent" were sufficient to allow them to give their own informed consent to medical treatment. ${ }^{75}$ In addition, the Coordinating Council on Life-Sustaining Medical Treatment Decision Making by the Courts, which developed Guidelines for State Court Decision Making in Life Sustaining Medical Treatment Cases, assumed that judges would need guidance in dealing with the LSMT preferences of mature minors and made special, albeit separate, provision for them. ${ }^{76}$

\section{Mature Minor Doctrine: One response to the need to allow minors to refuse or consent to medical treatment}

Despite judicial and legislative exceptions to the parental consent requirement, and despite the assumptions made in the legal and medical literature that mature minors have the right to make their own LSMT decisions, the parental consent requirement is still the law in most states. In response to the perceived unfair limitations posed by uniform application of this parental consent requirement and in recognition of the growing consensus in law and medicine that some minors possess actual capacity to make informed medical decisions, a few states have begun to carve out an exception to the common law rule of parental consent. Under this exception, commonly called the mature minor doctrine, a minor is allowed to refuse or consent to medical treatment if she possesses sufficient maturity to understand and appreciate the benefits and risks of the proposed medical treatment. ${ }^{77}$ Early in its development the mature minor doctrine was mainly invoked as an escape hatch for hard cases that did not fit into either the emergency exception or the medical necessity exception. These were usually cases of high benefit and low risk medical treatment decisions. ${ }^{78}$ In recent years, however, some courts have gone out of their way to address the question of whether minors who have capacity to make decisions about medical care should be allowed legally to do so. ${ }^{79}$

In re E.G. ${ }^{80}$ is the leading case addressing the issue of whether a mature minor has the right to make high stakes medical decisions. Ernestine Gregory (E.G.) was seventeen and a member of the Jehovah's Witness faith when she was diagnosed with leukemia. She and her mother refused to consent to a potentially life-saving blood transfusion for Ernestine. The case was originally brought before the courts as a medical neglect proceeding against the mother who had refused a blood transfusion on Ernestine's behalf. It was then appealed on grounds that E.G., as a mature minor, had the right to refuse blood transfusions through her first amendment right freely to exercise her religion. The Illinois Supreme Court, however, chose to confront directly the question of whether a mature minor had the legal right to refuse life saving medical treatment. In reaching their conclusion that ". . . a mature minor may exercise a common law right to consent to or refuse medical care. ..." ${ }^{\prime 1}$ the judges observed that the age of majority "is not an impenetrable barrier that magically precludes a minor from possessing and exercising certain rights normally associated with adulthood." 82 The court pointed out a number of circumstances where the law already recognized the legal capacity of minors, including the fact that if Ernestine had been married she could have consented to or refused treatment under Illinois statute. ${ }^{83}$ The court also noted that the criminal justice system already recognizes that certain minors possess adult maturity, emphasizing that Illinois' Juvenile Court Act made it clear that the age eighteen was not a "bright line" restriction. Rather, it allowed for the possibility of "individuals much younger than 18 " to be "prosecuted under the Criminal Code, if circumstances dictate." 84 The court reviewed several United States Supreme Court opinions that indicated a bright line age restriction of eighteen would be untenable if it restricts the constitutional rights of mature minors.

In holding that a mature minor has a right to refuse life saving medical treatment the court seemed to break sharply with the common law requirement of parental consent. The court, however, went on to place considerable emphasis on the fact that Ernestine's mother had actually agreed with her daughter's decision to refuse a blood transfusion. The court further stated that any opposition to a mature minor's decision from "parents, guardians, adult siblings, and other relatives would weigh heavily against the minor's right to refuse." 85 Alan Meisel, in his comprehensive text on the area of right-to-die law, found untenable the court's contention that objections from parents or other family member third parties should weigh heavily against the mature minor's right to refuse treatment. As he pointed out, "there seems to be no more ground for considering these objections in the case of a mature minor than in the case of an adult. And in the case of adults, the interests of third parties have been given increasingly short shrift." ${ }^{86}$ Not surprisingly, other commentators took the diametrically opposed position that the E.G. court had gone too far in granting a mature minor the right to refuse life saving treatment, characterizing the decision as a judicial trend toward "death over life,"

Belcher v. Charleston Area Medical Center ${ }^{89}$ is another significant case in which a state court recognized the mature minor doctrine. Larry Belcher, who was seventeen and had muscular dystrophy, suffered a respiratory arrest. His parents told the physician not to resuscitate Larry if he 
had another arrest unless Larry himself requested it. The physician wrote a DNR order without consulting Larry and the following day Larry had another arrest, was not resuscitated, and died. His parents sued the hospital and doctor for wrongful death, alleging lack of informed consent because Larry had not consented to the DNR. The West Virginia Supreme Court of Appeals held that a physician is required to obtain a mature minor patient's consent before administering or withholding treatment. ${ }^{90}$ Belcher is especially significant because it is the only court decision that creates a strong incentive for physicians to determine the maturity of their minor patients. If a physician fails to obtain a mature minor's consent before proceeding with treatment he may be held liable for wrongful death or could face other legal action.

\section{Weaknesses of the Mature Minor Doctrine as applied to LSMT}

The relevance of these two cases to the situation presented in our Prologue lies not in their precise factual similarity, but in that they are instances where a court held that there is a legal obligation to give effect to a mature minor's choices. The fundamental problems, however, of who decides whether a minor is mature enough to make her own decisions about LSMT, and whether she is then legally empowered to do so, are not systematically resolved by the cases. For instance, the two cases that we just examined come to quite different conclusions about who should determine a minor's capacity to make high stakes medical decisions and how it could be done.

In In re E.G. the Illinois Supreme Court noted that although the testimony of a psychiatrist with expertise in evaluating the maturity and competency of the minor in this case was presented at trial, ultimately it was the "trial judge who must determine whether a minor is mature enough to make health care choices on her own." court did not, however, explain how a minor wishing to have her maturity evaluated would have access to the trial judge. Instead, the judges appear to make an a priori assumption that there is some procedure already in place allowing for the assessment of a minor's maturity. The court did not explain how a minor who is chronically, perhaps terminally, ill could have the question of her maturity to make medical decisions resolved in real time. ${ }^{92}$ In fact, as the medical-legal system currently functions, a chronically ill mature minor who wants autonomy in medical decision making does not have access to legal representation or the court unless she wishes to be emancipated (which is highly unlikely, since most chronically ill children need to live with their families) or her physician suspects child abuse or neglect. Although the E.G. decision enhances the common law basis for a mature minor's right to refuse treatment, the entire legal process in this case began as a hearing of medical neglect because Ernestine's mother refused consent to transfusion. Without this neglect charge as a means of getting the trial court involved, Ernestine, who lived with her mother and would definitely not have qualified as an emancipated minor, would have had no way to obtain a court order to allow her to independently consent to or refuse medical treatment. Parental consent to LSMT effectively precludes a neglect proceeding. ${ }^{93}$ Thus, while the E.G. case recognized the rights of mature minors to refuse medical treatment, it did not establish workable procedures for implementing these rights for a minor with a chronic illness. $^{94}$

On the other hand, the West Virginia Supreme Court of Appeals in Belcher implied that physicians have an affirmative duty to discover whether their patients are mature before issuing DNR orders. ${ }^{95}$ The court held that if a physician concludes that the minor is mature, then he must elicit and follow the minor's choices, even over the objections of the parents. ${ }^{96}$ While recognizing that "it is obvious that this places the doctor in the difficult position of making the determination of whether the minor at issue is mature" and granting that "the decision by the doctor on the maturity level of a minor will often be second guessed," the court still concluded that the decision whether to allow a minor to make his own medical choices should be made by the patient's doctor using "his or her best medical judgment." ${ }^{\prime 97}$ Indeed, the Belcher court went so far as to say that the physician who makes a good faith assessment of the minor's maturity level would be immunized from liability for the failure to obtain parental consent if the parents disagreed with the minor's decision. ${ }^{98}$ This promise of immunity places a tremendous burden on the physician, a burden that not many physicians would be willing to shoulder. As with the E.G. decision, it is difficult to see how Larry Belcher could have asserted his right to make the decision to refuse or insist upon resuscitation. Larry Belcher's case reached the court only because his parents were distressed that the physician had ordered the DNR order placed on Larry's chart without consulting Larry first. Thus, after Larry's death they brought a wrongful death suit. Neither the case nor the subsequent statute ${ }^{99}$ sets out clear procedures for mature minors to accept or refuse medical treatment independently.

A major obstacle to establishing a coherent system for applying the mature minor doctrine to LSMT cases is that while there is a Constitutional dimension to the individual's right of privacy and bodily integrity and mature minors share to some degree in this protection, ${ }^{100}$ the Supreme Court has not stated the precise degree of protection that must be afforded patient autonomy ${ }^{101}$ and has not made clear whether this protection applies to all patients with the capacity to make decisions about end-of-life care. The lack of clear Constitutional protection for the patient's right to medical autonomy has meant that the courts have shifted 
away from basing their LSMT decisions upon Constitutional law and have moved towards a common law solution. ${ }^{102}$ Reliance upon the common law leaves the mature minor doctrine highly vulnerable to a wide array of interpretations by state and federal courts. ${ }^{103}$ The United States Congress' exclusion of minors from the PSDA ${ }^{104}$ further contributes to this non-systematic approach to the medical treatment of mature minors. Thus, the mature minor doctrine does not yet offer a legal framework that can accommodate a mature minor who wishes to make autonomous LSMT decisions.

\section{Response to arguments against a mature minor's right to refuse LSMT}

\section{State's interest in protecting human life}

Legal commentators have argued that in giving minors the autonomy to refuse medical treatment the State disregards its own interest in the preservation of life and its parens patriae duty to protect minors. These commentators, however, fail to address the essential difference between LSMT and life saving treatment. ${ }^{105}$ This is not a mere semantic difference. ${ }^{106}$ It is the difference between potentially painful treatment that nonetheless has a reasonable chance of saving a life, and treatment which, at best, forestalls the moment of death, and at worst inflicts the sort of misery described in our prologue. Without an honest discussion of this crucial difference, it is pointless to discuss whether the State's interest in protecting the minor's life trumps the mature minor's right to medical autonomy. A mature minor's refusal of LSMT cannot accurately be considered a fatal error from which she must be protected. Rather, it must be recognized and supported as her personal choice about how much suffering she wants to endure at the end of her life. ${ }^{107}$ To deny a mature minor autonomy to make LSMT decisions amounts to giving someone else the power to decide how she will die.

\section{Weakening of family bonds}

An argument has been made that granting a mature minor autonomy to make LSMT decisions weakens the family bond, detracts from parental rights, or disrupts a delicate familial balance uniquely understood by its members. ${ }^{108}$ In 1994 a group of academic health care providers confronted squarely the controversial question of whether an adolescent, whom the physician knows to be cognitively and psychosocially mature and able to ascertain his own best interest, should have the autonomy to refuse LSMT even in the face of parental objections. ${ }^{109}$ The group answered that in those instances where the views of the mature adolescent and his parents cannot be reconciled despite repeated discussion and ethics consultation, "the physician should re- spect the adolescent's decision, informing the parent that the health care team cannot morally accept surrogate decision making for a patient who is functionally autonomous." 110 While making it clear that they did not wish their stance to minimize the role of the patient's family, the authors made the key distinction that the health care professional's first moral obligation is to the patient. ${ }^{111}$

\section{Parents will always act in their child's best interest}

It is tempting to assume that as long as physicians give parents adequate information that parents will always make the best decisions about their children's medical care. There are several reasons, however, why parents may not necessarily make the best choices. For instance, as Lisa Hawkins has pointed out, "parents' judgment concerning life-sustaining treatment may be clouded by religious views not shared by the minor ... by their own needs (or those of other family members) ... and (most directly) by their own grief and sense of powerlessness." 112 As Rosato has said, " $[t]$ he strength of the minor's right to self-determination is truly tested" in the situation where the minor refuses treatment, but the parents consent. ${ }^{113}$ If a mature minor does not wish to undergo LSMT then it is her own judgment about how she wants to die that ultimately must be honored by the physician.

\section{Criteria for maturity too subjective}

Another objection has been raised that even if some minors have the capacity to make decisions about LSMT, it is simply too difficult to develop criteria for determining whether an individual patient is a mature minor. ${ }^{114}$ In fact, the judicial and medical professions have already supplied guidelines for assessing a minor's decision making capacity. Cardwell set out the following formulation for judging capacity, which was relied upon by the Belcher court: "Whether a minor has the capacity to consent to medical treatment depends upon the age, ability, experience, education, training, and degree of maturity or judgment obtained by the minor, as well as upon the conduct and demeanor of the minor at the time of the incident involved. Moreover, the totality of the circumstances, the nature of the treatment and its risks or probable consequences, the minor's ability to appreciate the risks and consequences are to be considered."115 The medical profession, as exemplified by the AAP's statements ${ }^{116}$ and the MBC Guidelines, ${ }^{117}$ has offered a similar formulation for determining decision making capacity.

Further objection has been raised that the judicial framework is too weak to "support the weight of a decision that bears such grave consequences." 18 This is not borne out in other areas of the law. For instance, in the area of criminal justice, where the stakes may also be life and death, 
many states have adopted laws that allow minors to be tried as adults. These states have developed standards and techniques for determining whether minors have the capacity to formulate the necessary intent to commit the crimes. ${ }^{119}$ While comparisons with the criminal justice system are not precisely analogous, it is significant that when states find it important to be able to evaluate a minor's ability to formulate criminal intent, standards are developed and implemented.

In fact, judges make determinations of competence all the time ${ }^{120}$ and courts are already beginning to accept the responsibility for determining the maturity of minors. ${ }^{121}$ The courts are in the best position to develop and apply standards. There is no institution "better equipped to weigh the facts of a given situation and arrive at a reasoned decision." 122

\section{Proposed solution: cooperation between medicine and law}

We believe that the medical and legal professions should work together to develop a process for determining whether minors who are chronically ill with potentially fatal illnesses have the capacity to understand their treatment options. When a minor has this capacity she must be given information about advance directives. If she chooses not to prolong her own dying process, her physician, her parents and the legal system must honor this choice. In order to achieve this goal what is needed is a systematic approach that is more practical, predictable, and standardized than what has thus far been proposed by other authors. The foundation of our proposed solution is built with elements culled from some earlier authors' suggested solutions, specifically from the MBC Guidelines, several law review articles, ${ }^{123}$ the medical ethics literature, ${ }^{124}$ and the Guidelines for State Court Decision Making in Life-Sustaining Medical Treatment Cases. ${ }^{125}$ However, our proposal requires much greater cooperative and anticipatory efforts between the professions of law and medicine in order to provide the key practical ingredient that is indispensable yet generally overlooked: time.

We envision a new process that would allow the mature minor to petition the court directly if she has the requisite medical condition-a potentially fatal illness, and the requisite legal problem - a fundamental disagreement with her parents about end-of-life care. ${ }^{126}$ Practically speaking, patients will only realize that they have these two situations to resolve if their physician is obligated to discuss the possibility of death, alternative options for end-of-life care, and the nature and implementation of an advance directive. ${ }^{127}$ Physicians should be required to notify the court ${ }^{128}$ as soon as a minor patient has met four criteria: 1) She has a potentially fatal illness and wishes to make decisions about her end-of-life medical care, either verbally or via a written advance directive; 2 ) the physician deems the patient has full decision making capacity; 3 ) the patient's parents dis- agree with her decisions about end-of-life care and will not agree to honor her wishes; and 4) multiple attempts to resolve the conflict have been unsuccessful.

In cases of unresolved differences between a mature minor and her parents, a judicial hearing must ultimately determine whether she is legally competent to make her own decisions about how she dies. Time is of the essence in the truest sense here, for if the judge is to ever get a chance at a first person evaluation of the chronically ill minor's maturity, this must occur before the minor is rendered voiceless in the PICU.

\section{How it might work}

The mature minor needs time to be recognized as mature and to discuss her preferences. When children have chronic diseases there is always a foreseeable risk of reaching a crisis point, when decisions will need to be made regarding LSMT. Therefore, a physician who provides medical care to chronically ill minors should always anticipate this possibility and make an initial determination of whether his patient is a mature minor. ${ }^{129}$ He must then initiate an informed consent discussion with her that includes an explanation of LSMT. Over time the informed consent dialogue would encompass not only a discussion of the risks and benefits of therapies that have a chance, however small, of curing the patient, but would also address the possibility that the patient might die. The physician would need to present the various alternatives for medical care at the end of life, including LSMT, hospice, or palliative care-alternatives that may or may not be mutually exclusive.

Discussion of advance directives must become a part of the informed consent process for chronically ill pediatric patients with potentially fatal illnesses. The physician must give the patient the chance to document her decisions regarding the amount of pain and anxiety she is willing to endure while she is dying and to state at what point she wants the primary focus of her care to shift from prolonging her life to maximizing her comfort. The patient must also be allowed to choose her legal surrogate decision maker by means of a durable power of attorney for health care. This would allow parents (or named others) to act as true surrogates who are willing to carry out the minor's wishes, thus fully protecting her right to her autonomy and self determination. ${ }^{130}$

Once the informed consent discussion regarding the anticipated plan for end-of-life medical care has occurred, patients, their parents, and physicians may well be in full agreement. The minor's advance directive might then be unnecessary, save as a means for alleviating some future parental self-doubt. If there is a conflict, however, the physician should honor his patient's, not the family's, wishes.

In cases of conflict between a patient and her parents there must be a timely, judicial bypass procedure to deter- 
mine whether the minor is mature enough to make her own decision about LSMT. ${ }^{131}$ In order to insure that the child's own preferences can be carried out without legal repercussions for physicians, the courts must become involved in deciding whether the individual minor is competent to refuse LSMT. In the Guidelines for State Court Decision Making in Life-Sustaining Medical Treatment Cases, for instance, judges are advised that unresolved conflict between the minor's preference and that of her parents "could very well create a justiciable issue" 132 and that the decision of whether a minor is mature "may necessitate a judicial determination." 133 The judicial bypass procedure assures physicians that there will be an opportunity for a speedy and efficient confirmation of their determination that their pediatric patient is capable of making her own decisions about LSMT. Early interaction between the medical and legal professions will also assist judges in LSMT cases by providing them with the luxury of more time to obtain the input from experts in medical matters and bioethics, input that judges say they want. ${ }^{134}$ Courts would then be in the best position to make a context-specific determination of the minor's competence to make LSMT decisions. ${ }^{135}$

A judicial bypass procedure can only take place, however, if the minor receives strong and active support from her physician, because a child who is mature and whose parents do not agree with her choice about end-of-life care will not have any other means by which to gain access to the courts. In addition, there is the possibility that if parents strongly object to their child's decisions about medical treatment, they may actively impede the physician's attempt to help the child get access to the courts. ${ }^{136}$ Therefore the physician's true commitment to the mature minor's medical autonomy will require that he assist her to gain access to the legal system and have her maturity adjudicated. ${ }^{137}$ There is a well-established precedent for the medical profession to contact the legal system in cases of suspected child abuse or medical neglect of minors. ${ }^{138}$ Just as the medical and legal communities have managed to create a functional system in these situations, they must now develop a system that accommodates mature minor patients who wish to make their own decisions about end-of-life care. For a new medicolegal protocol to do the right thing for mature minors, courts must willingly accommodate children with chronic illness, who may be in pain and/or may require a hospital rather than a courtroom hearing. ${ }^{139}$

Congress should also act by amending the PSDA to require hospitals to provide mature minors with information about the right to refuse medical treatment and the right to execute advance directives. ${ }^{140}$ An amended PSDA would create a minimum standard for patient notification ${ }^{141}$ of the right to refuse LSMT, and a process for familiarizing mature minor patients with the nature of an advance directive. While no states explicitly allow mature minors to execute advance directives or durable health care powers of attorney, a few state courts have decided cases that indicate that mature minors have a right to make decisions concerning medical care, including the right to accept or refuse medical treatment, and perhaps the right to create enforceable advance directives. ${ }^{142}$ By requiring hospitals to provide information to mature minors about state law, an amended PSDA would create an incentive for hospital officials to examine more fully the legal status of mature minors with respect to advance directives in their state. In turn, this could encourage a broader examination of the issues and might lead states to amend their own statutes to allow mature minors to execute advance directives. The PSDA requires hospitals not only to inform patients about their rights under state law, but also to provide education about advance directives to their staff and to the public. ${ }^{143}$ Thus, if minors were covered by the PSDA there would be a greater opportunity for them to become familiar with advance directives. Once mature minors begin to execute advance directives, cases involving the mature minor's right to refuse LSMT would come before the courts. Thus, much in the same way it did for adults, the PSDA could stimulate the medical and legal professions to develop standards and procedures that would facilitate the mature minor's ability to make and enforce decisions about end-of-life care.

State legislatures should also respond by enacting statutes that establish a substantive legal foundation for the mature minor's right to make autonomous medical decisions about LSMT. ${ }^{144}$ If the mature minor is statutorily empowered to give her own consent or refusal to LSMT, a physician who fails to consider his minor patient's maturity and treats her without her express consent could be held legally accountable. Such statutes would create an incentive for physicians to actively assess their minor patient's maturity when obtaining consent and to get a court determination of the minor's competence if there is a conflict between parent and child. ${ }^{145}$

It is not too much to ask for a multi-faceted response from courts, Congress, and state legislatures to a newly recognized ethical dilemma in medicine. Nor is it unrealistic. Adults were in little better position ten years ago with respect to the imposition of LSMT than mature minors are now and they got precisely the multi-faceted response we propose. ${ }^{146}$ The legal and medical professions must stop pretending that the imposition of treatment upon a child who has a strong chance of being cured of an illness is comparable to the imposition of LSMT on a child who does not wish to die in pain and isolation from her family and loved ones. For our professions to do any less than confront this reality and find a solution to the unwanted suffering that is being inflicted on children is an abdication of our moral and ethical responsibilities as physicians and lawyers. 


\section{References}

1. To date there is no research to document the frequency with which arguably mature minors might be receiving LSMT against their wishes. We therefore surveyed the medical directors of the eighteen pediatric ICUs in California that are approved by California Children's Services. Sixteen of the eighteen medical directors were interviewed. None of the medical directors had ever seen a written advance directive used by a patient less than eighteen years of age and all of them cared for many patients in the 15 to 17 year old age range. Thirteen directors could recall at least one occasion when they had been providing intensive care to an adolescent patient against that patient's own wishes. It seems reasonable to conclude that at least in California, the current medical system precludes minors of fifteen years and older, some of whom would be developmentally capable of understanding their medical condition, from executing an advance directive. It also permits these patients to be forced to receive LSMT. Many of these patients are at risk for the paralyzed but conscious type of death that we described in our prologue.

2. A. Meisel, The Right to Die, $2^{\text {nd }}$ ed., (New York:John Wiley,1995): Vol. 1, at 8 .

3. We will use the terms "minor" and "child" interchangeably. A "mature minor" is a child, generally an adolescent, who has decision making capacity.

4. In the Matter of Karen Quinlan, 355 A.2d 647, 663 (N.J., 1976) The Quinlan court also noted that "the respirator support cannot cure or improve her condition but at best can only prolong her inevitable slow deterioration and death." Id.

5. See Cruzan v. Director, Missouri Department of Health, 497 U.S. 261 (1990) (Justice Brennan dissenting, joined by Marshall and Blackmun). "The right to be free from unwanted medical attention is a right to evaluate the potential benefit of treatment and its possible consequences according to one's oun values and to make a personal decision whether to subject oneself to the intrusion. Id. at 309. [emphasis added].

6. See American Academy of Pediatrics Committee on Bioethics, "Guidelines on Forgoing Life-Sustaining Medical Treatment," Pediatrics 93 (1994): 532-36 [hereinafter AAP Guidelines on Forgoing LSMT] "The burdens of LSMT may include intractable pain; irremediable disability or helplessness; emotional suffering; invasive and/or inhumane interventions designed to sustain life; or other activities that severely detract from the patient's quality of life. (The phrase "quality of life" refers to the experience of life as viewed by the patient, i.e., how the patient, not the parents or health care providers, perceives or evaluates his or her existence. ... .)" Id. at 533 .

7. See Meisel, supra note 2, at 125 . "[m]inors are de jure incompetent by virtue of their age."

8. J.C. Hofmann, et al., "Patient Preferences For Communication With Physicians About End-Of-Life Decisions: SUPPORT Investigators Study to Understand Prognoses and Preferences for Outcomes and Risks of Treatment," Annals of Internal Medicine 127 (1997): 1-12; and The SUPPORT Principal Investigators, "A Controlled Trial to Improve Care For Seriously Ill Hospitalized Patients: The Study To Understand Prognoses And Preferences For Outcomes And Risks Of Treatment (SUPPORT)," JAMA 274 (1995): 1591-1598.

9. Pulmonary complications are quite common, occurring in $40-60 \%$ of bone marrow transplant recipients. A.O. Soubani, et al., "Pulmonary Complications of Bone Marrow Transplantation," Chest 109 (1996): 1066-1077. Not all pulmonary complications are respiratory failure, but this also occurs often. A $23 \%$ rate of post-BMT respiratory failure has been reported. S.W. Crawford and F.B. Petersen, "Long-Term Survival from Respira- tory Failure after Marrow Transplantation," American Review of Respiratory Disease. 145 (1992): 510-514.

10. Upwards of $85 \%$. See A.B. Warwick, et al., "Outcomes Following Mechanical Ventilation In Children Undergoing Bone Marrow Transplantation," Bone Marrow Transplantation 22 (1998): 787-794. See also G.D. Rubenfeld and S.W. Crawford, "Withdrawing Life Support from Mechanically Ventilated Recipients of Bone Marrow Transplants: A Case For Evidence-Based Guidelines," Annals of Internal Medicine 125 (1996): 625-633.

11. See J.D. Lantos, A.C. Berger, and A. R. Zucker, "Do-NotResuscitate Orders in A Children's Hospital," Critical Care Medicine. 21 (1993): 52-55, at 52, for the first study examining all deaths in a children's hospital. Eighty two per cent of the patient deaths occurred in the PICU, and discussions regarding DNR did not begin, in most cases, until patients were already in the PICU and on life-support. (at 55) See also M. Levetown, et al., "Limitations and Withdrawals of Medical Intervention in Pediatric Critical Care," JAMA, 272 (1994): 1271-1275, at 1274. This survey of 16 PICUs demonstrated that care restrictions were mainly based upon expectation of imminent death rather than upon chronic disease or quality of life considerations. Although $50 \%$ of these patients who had restrictions applied had "serious underlying illnesses." there was no discussion of advance directives or anticipation of death prior to PICU admission.

12. E. Morgan and S.B. Murphy, "Care of Children Who Are Dying of Cancer"(Editorial), N.Engl.J.Med. 342 (2000): 347-348.

13. A.P. Wheeler, "Sedation, Analgesia, And Paralysis in the Intensive Care Unit," Chest 104 (1993): 566-77.

14. K.A. Loper, et al., "Paralyzed with Pain: The Need for Education," Pain 37(1989): 315-316.

15. N. Moerman, B. Bonke, and J. Oosting, "Awareness and Recall During General Anesthesia," Anesthesiology 79 (1993): 454464 , at 454.

16. A.D. Macleod and E. Maycock, "Awareness During Anaesthesia and Post Traumatic Stress Disorder," Anaesthesia and Intensive Care 20 (1992): 378-382

17. D.R. Coursin and D.B. Coursin, "Survivors, Beware of Posttraumatic Stress Disorder: What Shall We Tell the Men in Black?" Critical Care Medicine 26 (1998): 634-635.

18. B.K. Wagner, et al., "Patient Recall of Therapeutic Paralysis in a Surgical Critical Care Unit," Pharmacotherapy 18 (1998): $358-363$ at 361 .

19. J.P. Gross, "Recollections of Children Experiencing Pharmacologic Paralysis," Dimensions of Critical Care Nursing, 11 (1992): 326-333.

20. L. D. Martin, S.L. Bratton, and P.P. O'Rourke, “Clinical Uses and Controversies of Neuromuscular Blocking Agents in Infants and Children," Critical Care Medicine 27 (1999): 13581368 at 1358.

21. See, for example, D.R. Goldhill and A. Sumner, "Outcome of Intensive Care Patients in A Group of British Intensive Care Units," Critical Care Medicine 26 (1998): 1337-45.

22. The only other potential physical clue to the patient's state of mind, their tears, is rarely a useful sign in the ICU where standard practice is to keep the patient's eyes frequently lubricated with ointment or artificial tears and taped shut to prevent severe abrasions of the eyeball surface.

23. See H. Brody, et al., "Withdrawing Intensive Life-Sustaining Treatment," N.Engl.J.Med. 336 (1997): 652-657.

24. See L.D. Martin, supra note 20, at 1358 , citing M.J. Murray, et al., The Use Of Neuromuscular Blocking Drugs In The Intensive Care Unit: A US Perspective, Intensive Care Medicine 19 (1993): S40-S44.

25. See T.P. Cahill, "Care Of The Dying: From An Ethics Per- 
spective," in Birth to Death: Science and Bioethics, D.C. Thomasma and T. Kushner, eds. (New York: Cambridge University Press, 1996) "... [ []n the case of the dying, where there is no cure, we must recognize the need for a different paradigm ... commonly called the paradigm of care. ..." Id. at 203. "No less aggressive on its own terms than curative medicine, palliative medicine provides active care when cure or prolongation of life is no longer possible." Id. at 204.

26. Because it is impossible, even in the most detailed document, to anticipate all possible medical treatment decisions, some have advocated having individuals list their personal"values history." Others have recommended that patients describe their goals of treatment. This approach to an advance directive is designed to instruct physicians and patient surrogates to make treatment decisions in accordance with the patient's values and goals of treatment, even if a given specific medical situation was not foreseen by the patient when she executed her advance directive. See, for example, D. Orentlicher, "The Limitations of Legislation," Maryland Law Review 53 (1994): 1255-1305, at 1258-59.

27. See, for example, H.J. Silverman, et al., "Implementation Of The Patient Self Determination Act In A Hospital Setting: An Initial Evaluation," Archives of Internal Medicine, 155 (1995): $502-510$. This survey finds only $15 \%$ of severely ill patients execute advance directives.

28. United States. President's Commission for the Study of Ethical Problems in Medicine and Biomedical and Behavioral Research. Deciding to Forego Life-Sustaining Treatment: A Report on the Ethical, Medical, and Legal Issues in Treatment Decisions. (The Commission: U.S.G.P.O. 1983): at 132.

29. Id.

30. Id. at 135 .

31. Id. at 136. "The Commission believes that, when possible, decision making for incapacitated patients should be guided by the principle of substituted judgment, which promotes the underlying values of self-determination and well-being better than the best interests standard does."

32. For a list of state durable power of attorney and living will statutes and a description of their provisions concerning the immunity of attending physicians from criminal and civil liability for complying with medical treatment decisions written in an advance directive or delivered through an agent, see, $\mathrm{R}$. Leiter, $\mathrm{Na}$ tional Survey Of State Laws, $3^{\text {rd }}$ ed., (Detroit: Gale Research, 1999): at 491-520 (durable power of attorney) and 527-556 (living wills).

33. Cruzan, 497 U.S. 262, at 286-87(1990).

34. The Patient Self-Determination Act (PSDA) was passed as part of the Omnibus Budget Reconciliation Act of 1990, P.L. 101$508, \$ 4206,104$ Stat. 1388 . The key provisions of the PSDA are contained in 42 U.S.C.S. $\$ 1395 \mathrm{cc}(\mathrm{a})(1)(\mathrm{Q}) ; 1395 \mathrm{cc}(\mathrm{f})(1)$; $1395 \mathrm{~mm}(\mathrm{c})(8) ; 1396 \mathrm{a}(\mathrm{a})(57)-1396 \mathrm{a}(\mathrm{a})(58) ; 1396 \mathrm{a}(\mathrm{w})$ (USCS Supp. 2000)

35. See id. at $1396 \mathrm{a}(58)$.

36. See $i d$. at $\$ 1395 \mathrm{cc}(\mathrm{f})(1)(\mathrm{A})(\mathrm{i})$, requiring hospitals and health care facilities to provide information concerning any state law relating to the patient's right to accept or refuse medical treatment that is recognized by the courts of the state, as well as an explanation of any right to die statue, durable power of attorney, or other relevant statute. For a summary of the Act's requirements, see B.R. Furrow, et al., Health Law, (St. Paul, Minn.: West, 1995 ): at $768-70$.

37. Leiter, supra note 32 , at 491-520 (durable power of attorney) and 527-556 (living wills).

38. At common law the right to refuse medical treatment is based on the right to control one's own body, to self-determina- tion and to freedom from invasion of bodily integrity. See Meisel, supra note 2 , at $37-77$, for a comprehensive review of the legal foundations of the right to die.

39. The New Jersey Supreme Court based its decision in the famous Quinlan case on the constitutional right to privacy. See Quinlan, supra note 4, at 663. However, the U.S. Supreme Court, in its first and only ruling in this area, based the right to refuse life sustaining medical treatment on the Fourteenth Amendment's guarantee of personal liberty. See Cruzan v. Director, Missouri Department of Health, 497 U.S. 261 (1990). See also, Meisel, supra note 2, vol. 1 at 61-64.

40. A. S. Berger, Dying and Death in Law and Medicine: $A$ Forensic Primer for Health and Legal Professionals (Westport, Conn: Praeger, 1993): at 97.

41. In other areas, such as criminal law or the competency of minors to testify as witnesses, the common law often applies the Rule of Sevens, under which minors under the age of 7 are irrebuttably presumed incompetent, minors between 7 and 14 were rebuttably presumed incompetent, and minors from 14 to 21 were rebuttably presumed competent. See, e.g. Cardwell $\nu$. Bechtol, 732 S. W. 2 d 739, at 745 (Tenn. 1987). (1979)

42. See, for example, Parham. v. J.R., 442 U.S. 584, 602-03

43. "To be valid, any consent must be an 'informed' one, and it must be given by a person with the requisite legal capacity. Thus, a physician who proceeds with what he considers to be treatment in conformity with the best interests of his minor patient, at that patient's request and with his agreement, still might be proceeding without legal consent because the minor may lack capacity to consent because of his age." W. Wadlington, "Minors and Health Care: The Age of Consent," Osgoode Hall Law Journal. 11 (1973): 115-25.

44. For a discussion of the emergency doctrine, see A.R. Holder, Legal Issues in Pediatrics and Adolescent Medicine. $2^{\text {nd }} \mathrm{ed}$. (New Haven: Yale University. Press, 1985): at 125-26.

45. See F.A. Rozovsky, Consent to Treatment: A Practical Guide. (Boston: Little, Brown, 1990): at 260.

46. See, A.R. Holder, "Circumstances Warranting Court-Ordered Medical Treatment of Minors," 24 American Jurisprudence Proof of Facts, $2^{\text {nd }}$ (Rochester, N.Y.: Lawyers Co-operative Pub. Co.: San Francisco, Calif.: Bancroft-Whitney Co.,1980, Supp. 1999): $169-210$

47. See "American Academy of Pediatrics: Informed Consent, Parental Permission, and Assent in Pediatric Practice," Pediatrics, 95 (1995): 314-317, at 316. The AAP admonishes parents and physicians against possible "abuses of raw power over children when ethical conflicts occur" in conflicts over decisions with the highest stakes, "the initiation, withholding, or withdrawing of lifesustaining treatment" and states that "... no one should solicit a patient's views without intending to weigh them seriously." Id. The AAP has advised physicians to give "considerable weight to the feelings minors may have before losing the capacity to communicate clearly regarding LSMT," and to respect any form of advance directive as "strong evidence of a patient's wishes." AAP Guidelines on Forgoing LSMT, supra note 6, at 535.

48. "The common law rule was and is that treatment of a minor, even without negligence and where the treatment led to a satisfactory result but for which the parents did not consent, gave rise to an action for assault and battery brought by the parents." A.R. Holder, Legal Issues in Pediatrics and Adolescent Medicine. $2^{\text {nd }}$ ed. (New Haven: Yale Univ. Press, 1985): at 124-25.

49. Powers $\nu$. Floyd, 904 S.W. 2d 713 (Tex. App.,1995), citing Macky v. Lucey Products Corp., 239 S.W. 2d 607 (Tex.,1951). The Powers case deals with a minor's right to consent to medical 
treatment in the abortion context.

50. See R. F. Weir, C. Peters, Affirming the Decisions Adolescents Make about Life and Death. Hastings Center Report, 27 no.6, (1997): 29-34, at 31. For a discussion of the competence of adolescents, see L. Weithorn and L.S. Campbell. "The Competency of Children and Adolescents to Make Informed Treatment Decisions," Child Development 53 (1982): 1589-98.

51. N.M.P. King and A.W. Cross, "Children as Decision Makers: Guidelines for Pediatricians," The Journal of Pediatrics, 115 (1989): 10-16.

52. Id. at 14 .

53. S. Leiken, "A Proposal Concerning Decisions to Forgo Life-Sustaining Treatment for Young People," The Journal of Pediatrics, 115 (1989): 17-22.

54. Id. at 18 .

55. Id. at 21.

56. AAP Guidelines on Forgoing LSMT, supra note 6, p. 532536; American Academy of Pediatrics, Informed Consent, Parental Permission, and Assent in Pediatric Practice. Pediatrics 95 (1995): 314-317; American Academy of Pediatrics, Ethics and the Care of Critically Ill Infants and Children. Pediatrics, 98 (1996): 149-152.

57. A.R. Fleischman, et al., "Caring for Gravely Ill Children," Pediatrics, 94 (1994): 433-439, at 434. The group also concluded that if such a child "voiced specific wishes prior to losing capacity, we believe the substituted judgment standard is applicable and supports respect of those wishes."

58. Midwest Bioethics Center Task Force on Health Care Rights for Minors, "Health Care Treatment Decision-Making Guidelines for Minors," Bioethics Forum, 11 no. 4 (1995): A/1 to A/15.

59. AAP Guidelines on Forgoing LSMT, supra note 6, at 532. 60. Id. at 535 .

61. Id.

62. See A. Holder, "Special Categories of Consent: Minors and Handicapped Newborns," Treatise on Health Care Law (New York: M. Bender, 1991, Supp. 1999): Vol. 3, ch.19, \$19.03[3][c].

63. At least three states have adopted the mature minor exception to the parental consent requirement. This exception may give minors the right to consent to or refuse certain medical treatment. See In re E.G. 549 N.E.2d 322 (Ill. S. Ct.,1989); Belcherv. Charleston Area Medical Center, 422 S.E.2d 827 (W. Va, 1992); Cardewell v. Bechtol, 724 S.W. 2d 739 (Tenn., 1987). In addition, Alabama allows minors 14 years or older to consent to medical treatment. See Ala. Code 1975 sec. 22-8-4. It is unclear whether or how Alabama's law would apply in a situation where a minor wishes to refuse LSMT and her parents want her to have it.

64. AAP Guidelines on Forgoing LSMT, supra note 6 , at 535 .

65. Wadlington, supra note 43, at 119.

66. Id. at 125 .

67. For a discussion of these exceptions, see L.A. Hawkins, "Living-Will Statutes: A Minor Oversight," Virginia Law Review. 78 (1992): 1581-1615, at 1586; J.L. Rosato, "The Ultimate Test of Autonomy: Should Minors Have a Right to Make Decisions Regarding Life-Sustaining Treatment?" 49 Rutgers Law Review 49 (1996): 1-103, at 25; W. Wadlington, "Children: Tensions Between Parent, State, and Child," University of Illinois Law Review 1994 (1994): 311-336, at 323-24.

68.See Belcher v. Charleston. 422 S.E. 2d 827, at 835 (W. Va. 1992), quoting Fay A. Rozovsky, Consent to Treatment, sec. 5.2, 2d ed. (1990), emphasizing that exceptions for medical emergencies, the emancipated minor, and the mature minor had already made an "inroad" into the traditional common law requirement that parental consent to medical treatment was always required. They attributed this "more enlightened attitude toward the mi- nor" to case law and legislative action and suggested "recognition that minors who are mature may be involved in the medical decisions that affect their livelihood."

69. See, for example, Novak v. Cobb County-Kennestone Hospital Auth. 849 F.Supp 1559 at 1576 (Ga., 1994), aff'd., 74 F.3d 1173 (11th Cir. Ga. 1996) "These exceptions allow minors who are married, pregnant or have children the power to consent to medical treatment for themselves, their spouses and their children. Rather than support plaintiffs' position, however, these exceptions undermine it. If minors, "mature" or otherwise, possessed the power to consent to and/or refuse medical treatment, there would be no need for these specific statutory exceptions."

70. See W. Wadlington, Children: Tensions Between Parent, State, and Child. University of Illinois Law Review 1994 (1994): 311-336, at 323 .

71. Bellotti v. Baird, 443 U.S. 622, at 623 (1979), Planned Parenthood of Central Missouri v. Danforth, 428 U.S. 52, at 9091 (1976).

72. Bellotti v. Baird, 443 U.S. 643 (1979). For further discussion of a minor's right to abortion, see D.T. Kramer, Legal Rights of Children, $2^{\text {nd }}$ ed. (Colorado Springs: McGraw-Hill, 1994): at 649-658. For a detailed bibliography of law review articles on the topic of minors and abortion, see $i d$. at 650 , note 387 .

73. For a discussion of the minor's right to abortion, see Holder, supra note 62, chapter 19, $\$ 19.06[3][\mathrm{a}]-[\mathrm{c}]$.

74. Planned Parenthood of Central Missouri v. Danforth, 428 U.S. 52 at 74 (1976). See also, In re Gault, 387 U.S. 1, 13 (1967). “... whatever may be their precise impact, neither the Fourteenth Amendment nor the Bill of Rights is for adults alone."

75. J.M. Morissey, A.D. Hofman, and J.C. Thorpe. Consent and Confidentiality in the Health Care of Children and Adolescents: A Legal Guide. (New York: The Free Press,1986): at 16.

76. "If the preferences of an LSMT patient who is a nonemancipated but mature minor can be ascertained, such preferences should be given great weight in determining what is in the minor's best interest." Coordinating Council on Life-Sustaining Medical Treatment Decision Making by the Courts. Guidelines for State Court Decision Making in Life Sustaining Medical Treatment Cases, Revised $2^{\text {nd }}$ ed., (St. Paul, Minn: West, 1993). Guideline 23, at 115. [hereinafter Coordinating Council]. See also Commentary: "A surrogate decision maker evaluating what is in the minor's best interests should attempt to determine whether the minor has expressed a preference regarding LSMT ... Where this preference reflects mature consideration on the part of the minor, the expressed preference should be given great weight." Id. at 116.

77. See Meisel, supra note 2, Vol. 2 at p. 276-79.

78. For a discussion of the origins of the doctrine, see Wadlington, supra note 43 at 117.

79. For example, see, In re E.G. 549 N.E.2d 322 (Ill. S. Ct.,1989); In re Rosebush, 491 N.W.2d 633 (Mich. App., 1992); In re Swan, 69 A.2d 1202 (Me., 1990); Belcher v. Charleston Area Medical Center, 422 S.E.2d 827 (W. Va., 1992).

80. In re E.G., 549 N.E. 3 d 322 (Ill. S. Ct., 1989)

81. Id. at 328 .

82. Id. at 325 .

83. Id.

84. Id. at 326.

85. Id. at 328.

86. Meisel, supra note 2, at Vol. 2, p. 278-79.

87. W.D. Brewster, "Death over Life: A Judicial Trend Continues as the Illinois Supreme Court Grants Minors the Right to Refuse Life-Saving Medical Treatment," (Case note: In Re E.G., A Minor). John Marshall Law Review. 23 (1990): 771-786, cit- 
ing article title.

88. J.A. Penkower, "Comment: The Potential Right of Chronically-Ill Mature Minors to Refuse Life-Saving Medical TreatmentFatal Misuse of the Mature Minor Doctrine," De Paul Law Review 45 (1996): 1165-1216, citing article title.

89. Belcher v. Charleston Area Medical Center, 422 S.E. $2 \mathrm{~d}$ 827 (W. Va., 1992)

90. Id. at 838. The West Virginia legislature subsequently enacted W. Va. Code $\$ 16-30 \mathrm{C}-6$, which states:

If the minor is between the ages of sixteen and eighteen, and in the opinion of the attending physician, the minor is of sufficient maturity to understand the nature and effect of a do not resuscitate order, then no such order shall be valid without the consent of such minor. In the event of a conflict between the wishes of the parents or guardians and the wishes of the mature minor, the wishes of the mature minor shall prevail.

W. Va. Code $\$ 16-30 \mathrm{C}-6$ (d). The statute seems to be limited to DNR orders (not all medical treatment) and applies only to minors 16-18.

91. In re E.G. supra note 80 , at 327 .

92. See I. Traugott and A. Alpers, "In Their Own Hands: Adolescents' Refusals of Medical Treatment," Archives of Pediatric and Adolescent Medicine 151 (1997): 922-927. The three adolescent patients they present were seriously ill and "recourse to the judicial system may have been impractical." Id. at 927

93. See J.F. Skeels, "In re E.G.: The Right of Mature Minors in Illinois to Refuse Lifesaving Medical Treatment," Loyola University Law Journal 21 (1990): 1199-1230, at 1222-23.

94. See $i d$. at $1222-1224$, for a review of the practical difficulties involved when health care providers are dealing with a mature minor who disagrees with her parents.

95. See Belcher, supra note 89: "Furthermore, it is obvious that this places the doctor in the difficult position of making the determination of whether the minor at issue is mature. ... Consequently, the doctor, as in every other decision with which he or she is faced, must exercise his or her best medical judgment." Id. at 837 .

96. Id. at 838

97. Id. at 837 .

98. Id. at 838 .

99. W. Va. Code $\ 16-30 \mathrm{C}-6$

100. See S.D. Hawkins, "Note: Protecting the Rights and Interests of Competent Minors in Litigated Medical Treatment Disputes," Fordham Law Review 64 (1996): 2075-2132, at 209495.

101. See Hawkins, supra note 67 , at 1609 , citing Cruzan.

102. See Meisel, supra note 2, vol. 1, at 61-66.

103. See, for example, O.G. v. Baum, 790 S.W. 2d 839, at 840-42 (Tex. Ct. App. 1990), (Sixteen year old Jehovah's Witness refused, with his father's agreement, blood transfusions deemed necessary by minor's physician. The court concluded that Texas had not adopted the mature minor standard and thus would not allow minor to refuse transfusions on his own behalf.); See also, Opinion of the Attorney General of Louisiana, No. 88-232 (Nov. 16, 1988). (A mature minor may consent to treatment, but may not refuse it over his parents' objections.); Novak v. Cobb-CountyKennestone Hospital Auth., 849 F.Supp 1559 at 1576 (Ga.,1994), aff'd., 74 F.3d 1173, 1996 (11th Cir. Ga. 1996) (The mature minor exception is not recognized in Georgia.); J.M. Kun, Rejecting the Adage "Children Should be Seen and Not Heard-The Mature Minor Doctrine," Pace Law Review 15 (1996): 423-462, at 439-42 (discussion of O.G. $v$. Baum)

104. 42 U.S.C.A. $\$ 1395 \mathrm{cc}(\mathrm{f})(1)$
105. See, for example, Brewster, supra note 87, at 779-780; Penkower, supra note 88; and L.F. Ross, "Arguments Against Health Care Autonomy for Minors," Bioethics Forum, 11 no. 4 (1995): $22-26$, at 24. These authors never discuss the term life sustaining medical treatment, nor do they make the distinction between life saving and life sustaining medical treatment. Even strong supporters of the mature minor's right to make life and death medical decisions confuse life saving medical treatment and LSMT. See, for example, Rosato, supra note 67 , at 68 . See also, Traugott, supra note 92 , at 924 .

106. See L.A. Hawkins, supra note 101, at 1595.

107. Id. at 1596." . . the living-will decision is one in which the benefits and costs are themselves dependent upon personal values."

108. L.F. Ross, "Arguments Against Health Care Autonomy for Minors," Bioethics Forum, 11 no. 4 (1995): 22-26, at 23-24.

109. See Fleischman, supra note 57 , at 437.

110. Id.

111. Id. See also, C. Strong, "Respecting the Health Care Decision-Making Capacity of Minors," Bioethics Forum, 11, no 4 (1995): 7-12, at 8-9.

112. L.A. Hawkins, supra note 101 at 1611-12.

113. Rosato, supra note 67 , at 8.

114. See M. Oberman, "Minor Rights and Wrongs," Journal of Law, Medicine $\mathcal{F}$ Ethics 24 (1996): 127-38, at 134. See also, Penkower, supra note 88, at 1169 and 1211-12.

115. Cardwell v. Bechtol, 732 S. W. 2d 739 at 748 (Tenn. 1987). This formulation was followed in Belcher, supra note 89, at 836 .

116. See AAP Guidelines on Forgoing LSMT, supra note 6 , at 532.

117. See Midwest Bioethics Center Task Force on Health Care Rights for Minors, supra note 58, at A/3 "An individual with decisional capacity has the ability to make a specific decision, i.e., the ability to understand relevant information, to reflect upon it and to communicate the decision (verbally or non-verbally) to providers."

118. Penkower, supra note 88, at 1191.

119. These comparisons have been lucidly pointed out by the E.G. court: ". . . the Juvenile Court Act presupposes a "sliding scale of maturity" in which young minors can be deemed mature enough to possess certain mental states and be tried and convicted as adults. ... When a minor is mature enough to have the capacity for formulate criminal intent, both the common law and our Juvenile Court Act treat the minor as an adult." In re E.G. 549 N.E. 2 d 322 , at 326 (Ill. 1989)

120. For a detailed discussion of judicial determinations of minors' competence to make a variety of decisions, including abortion, medical treatment, political expression and Miranda rights, see Rosato, supra note 113, at 50-54. 1240 (1999)

121. See, for example, In the Matter of A.M.P. 708 N.E. $2 d 1235$, at 1240 (N.J. 1999), in which the court found that a hearing must be held to determine whether a patient is a mature minor who is competent to make a reasoned decision to undergo electroshock therapy.

122. N. Batterman. Under Age: A Minor's Right to Consent To Health Care. Touro Law Review 10 (1994): 637-678, at 673.

123. Rosato, supra note 113; L.A. Hawkins, supra note 101 , Batterman, supra note 122, and Skeels, supra note 93.

124. See, generally, Weir, supra. note 50, and L.J. Schneiderman and S. Manning, "The Baby K Case: A Search for the Elusive Standard of Medical Care," Cambridge Quarterly of Healthcare Ethics. 6 (1997): 9-18.

125. Coordinating Council, supra note 76.

126. If one or both parents or the patient's physician were 
opposed to a mature minor's choice it would be exceedingly difficult for the patient to reach the court, even under our proposed solution. If the mature minor's right to make autonomous decisions about LSMT were more clearly delineated, a minor might then have recourse to an agency, such as child protective services, to assist her in getting into court.

127. While it is beyond the scope of this paper to discuss minors who do not have fully developed capacity, we believe that the imposition of LSMT upon these children without some attempt to elicit their preferences is also wrong. Indeed, the State may have an affirmative responsibility to the immature minor to alleviate unnecessary suffering. See, for example, In re Conroy, 486 A.2d 1209 (NJ, 1985):

[We] hesitate, however, to foreclose the possibility of humane actions, which may involve termination of life-sustaining treatment, for persons who never clearly expressed their desires about life-sustaining treatment but who are now suffering a prolonged and painful death. An incompetent, like a minor child, is a ward of the state, and the state's parens patriae power supports the authority of its courts to allow decisions to be made for an incompetent that serve the incompetent's best interests, even if the person's wishes cannot be clearly established.

Id. at 1231.

128. See Traugott, supra note 92, at 926. Pediatricians are already accustomed to petitioning the court when parents refuse consent to life saving medical treatment on a religious basis. See also, S.D. Hawkins, supra note 100 , at 2087 , note 88 , for citations to a number of court-ordered transfusion cases.

129. The need for anticipatory decision making has been emphasized: "Moreover, when specific life-sustaining measures will predictably become an issue in a specific clinical context, it obviously makes sense to discuss those measures in advance (e.g. mechanical ventilation for patients with severe emphysema)." A.S. Brett, "Limitations of Listing Specific Medical Interventions in Advance Directives," JAMA. 266 (1991): 825-828, at 828.

130. The AAP asserted that the substituted judgment standard should be used "for children who are emancipated or mature when their wishes are known or may be deduced." AAP Guidelines on Forgoing LSMT, supra note 6, at 535. See also, In re Rosebush, 491 N.W. 2d 633, at 637 (MI. 1992): “[I]n making decisions for minors or other incompetent patients, surrogate decision makers should make the best approximation of the patient's preference on the basis of available evidence. ... Under the proper circumstances-where a patient was formerly competent or is a minor of mature judgment-the substituted judgment standard is an appropriate test." Id. at 639 .

131. This has been suggested by Traugott, supra note 92, at 926-927

132. Coordinating Council, supra note 76, at 112.

133. Id. at $110-11$.

134. Id. at 18.

135. See Meisel, supra note 2, vol 1, at 144 , for a discussion of the emerging consensus that competence is not an all or nothing condition, but is often context-specific.

136. One of the reasons the U.S. Supreme Court gave for insisting that a pregnant minor be able to go directly to the court without notifying her parents is that parents who were opposed to abortion would block their child's access to the court. See Bellotti v. Baird, 443 U.S. 622, at 647-48 (1979)

137. Although an independent advocate is the best legal representation for a minor, she will have difficulty seeking out and paying for an attorney. As medical treatment cases are civil pro- ceedings, there may be no constitutional right to representation. See S.D. Hawkins, supra note 100, at 2104. For an example of a court that does appoint an attorney in cases involving the withdrawal of LSMT from minors, see Los Angeles County Superior Court Rule 17.4. Life Sustaining Medical Treatment. (Before ordering the withdrawal of LSMT for minors subject to juvenile court jurisdiction the court must appoint an attorney to represent the minor, if the minor does not have an attorney.) id. at 17.4(a) and $17.4(\mathrm{~g})(1)$.

138. See L.B. Mark, "The Competent Child's Preferences in Critical Medical Decisions: A Proposal for its Consideration," Western State University Law Review 11 (1983): 25-58, at 52-53.

139. See Coordinating Council, supra note 76 , at $87-88$, recommending that an exception to the "general rule against viewing the patient" occur when the court needs to address "the competency of the patient" and the patient is too ill to come to the courthouse.

140. Of course, the PSDA is not a panacea. "The concern has been expressed that the PSDA is "motivated less by a genuine respect for actual informed patient choice than by the feeling that physicians and hospitals now need not trouble themselves in making truly critical and sometimes agonizing decisions." Anecdotal evidence suggests that the statute has not had the effect of encouraging physicians to initiate end of life discussions with patients." Meisel, supra note 2, vol 2 at 54, citing E.H. Loewy, "Advance Directives and Surrogate Laws: Ethical Instruments or Moral CopOut?" Archives of Internal Medicine 152(1992): 1973-76, at 1973.

141. Special Report, Sources of Concern about the Patient SelfDetermination Act, N.Engl.J.Med 325 (1991): 1666-71, at 1670. "The PSDA's requirements must become not a ceiling but a floor."

142. At least two state courts have concluded that minors have a right to have their previously stated end-of-life preferences honored. In In re Chad Swan, 569 A.2d 1202, 1206 (ME. 1990) the Maine court gave authority to a seventeen year old's verbally expressed, but "well-formed desires as to medical treatment." (a previously stated desire to avoid LSMT). The court considered Chad Swan's age as only one factor in evaluating the seriousness of his stated preferences. Id. at 1205. In In re Rosebush, 491 N.W. 2d 633, (MI. 1992) the Michigan Court of Appeals concluded that " $[t]$ he advance directive of a mature minor, stating the desire that life-sustaining treatment be refused, should be taken into consideration or enforced when deciding whether to terminate the minor's life support treatment or refuse medical treatment." Id. at 636 , note 4 . Nor can hospitals subject to the PSDA's requirements assume that their advance directive and/or durable power of attorney statutes are the only acceptable means for stating one's end-of-life preferences. See, for example, Conservatorship of Drabick, 245 Cal. Rptr. 840 (1988), holding that neither California's Natural Death Act nor its Durable Power of Attorney for Health Care statute were the exclusive means by which a person could express legally cognizable preferences about LSMT.

143. 42 USCS $\$ 1395 \mathrm{cc}(\mathrm{f})(1)(\mathrm{E})$.

144. See Batterman, supra note 122, at 673; and S.C. Lonowski, "Recognizing the Right of Terminally-Ill Mature Minors to Refuse Life-Sustaining Medical Treatment: The Need for Legislative Guidelines to Give Full Effect to Minors' Expanded Rights", University of Louisville Joumal of Family Law 34 (1996): 421-45, at 443.

145. See Belcher, supra note 89. Physician was found to have a duty to obtain consent of a mature minor patient before issuing a DNR order.

146. For a review of the landmark cases involving discontinuing LSMT, see G.M. Burnell, Final Choices (New York: Insight Books, 1993): at 215-16 and 220-222. 